Artigo 


\title{
CIDADE DE GOIÁS: 0 CHEIRO DAS ÁGUAS, AS ÁGUAS DE CHEIR0 E AS ALELUIAS (1880-1899)
}

\author{
CITY OF GOIÁS: THE SMELL OF WATER, THE FRAGANCE, AND THE \\ HALLELUJAHS (1880-1899)
}

VILLE DE GOIÁS: L'ODEUR DES EAUX, LES PARFUMS ET LES ALLÉLUIAS (1880-1899)

\author{
Carlos Eduardo S. Maia - Universidade Federal de Goiás \\ carlmaia@uol.com.br
}

\begin{abstract}
Resumo
No presente trabalho, procura-se resgatar o ciclo festivo Carnaval-Quaresma-Páscoa na Cidade de Goiás no final do século XIX, momento em que esta, apesar de centralizar as funções administrativas da Província de Goyaz e, posteriormente, do Estado, sustentava-se numa sociedade agrária que rompera com a crise da mineração e tinha na produção agro-pastoril sua base econômica. Apesar desta dinâmica econômica agrária, em que o campo era a core área econômica, a cidade impunha-se como o centro administrativo, cultural e também demográfico, pois o ouro produziu um núcleo urbano de casario colonial e fixou a população vilaboense às margens do Rio Vermelho. Tudo isto fazia das festas urbanas momentos de efervescência em que a paisagem recebia sons, cheiros, cores, movimentos, etc. Mas cabe aqui um parêntese: dado que a dinâmica da economia goiana era agrária, ganhava especial atenção as festas em que "a roça" e a "cidade" se encontravam, principalmente nas folias e procissões em "festas da Igreja", destacando-se, no caso estudado, as celebrações da quaresma e da Páscoa.
\end{abstract}

Palavras-chave: Festa popular. Carnaval, Cidade de Goiás. Quaresma.

\begin{abstract}
This study focuses on the festive cycle Carnival-Lent-Easter in the City of Goiás, during the late nineteenth century. At that moment that, the administrative functions were centralized in the Province of Goyaz (the actual State of Goiás) and were sustained by an agrarian society, as the rural resources became its economic basis after the end of the mining cycle. Despite the importance of these resources, which placed the country side as the economic core area, the city imposed itself as the administrative center, cultural and demographic center. Because of the exploitation of gold, an urban center of colonial houses, with the vilaboense population set on the banks of the Rio Vermelho, had been created. This was the urban festival, moments of effervescence in which the landscape received sounds, smells, colors, movements, etc. Since the dynamics of the Goiás economy was agrarian, the "farm" and "city" were the dominant elements in the folias and processions, or "festivals of the Church", especially in the case studied, the celebrations of Lent and Easter.
\end{abstract}

Key-words: Folk celebrations. Carnival. City of Goiás. Lent.

\section{Résumé}

Ce travail vise à racheter le cycle de Carnaval-Carême-fête de Pâques dans la ville de Goiás à la fin du XIXe siècle, lorsque celle, en dépit de la centralisation des fonctions administratives de la province de Goyaz et, ultérieurement, l'État, est fondée dans une société agraire qui a rompu avec la crise sur l'exploitation minière et la production agro-pastorale était sa base économique. En dépit de cette dynamique d'une économie agraire, où le rural était le cœur économique, la ville s'est imposée comme le centre administratif, culturel et démographique, car l'or a produit un noyau urbain de maisons coloniales autant qu'a établi la population vilaboense sur les rives du Rio Vermelho. Ainsi, la ville a été prise par des moments d'effervescence pendant les fêtes et son paysage a reçu des sons, odeurs, couleurs, mouvements, etc. Mais il faut une parenthèse, parce que la dynamique de l'économie goiana était agraire, les célébrations qui ont relié le

\begin{tabular}{|l|l|l|l|l|l}
\hline Boletim Goiano de Geografia & Goiânia - Goiás - Brasil & v. 29 & n. 1 & p. 179-194 & jan. / jun. \\
\hline
\end{tabular}


«rural» et «ville» ont obtenu une attention particulière, notamment les processions et folias pendant "fêtes de l'église", principalement dans ce cas les célébrations de Carême et de Pâques.

Mots-clés: Fête populaire. Carnaval. Ville de Goiás. Carême.

\section{Convite}

As festas populares exemplificam aquilo que Mauss (2003) denominou de "fato social total", já que aí se exprimem de modo entrelaçado as instituições econômicas, jurídicas, religiosas, morais, políticas, além de fenômenos estéticos e morfológicos. Em sua dimensão simbólica, a festa se serve de uma infinidade de linguagens que estabelecem a comunicação entre os atores sociais implicados; já que, como exara Cassirer (1977), a linguagem é um fenômeno fundante do homem como ser simbólico e social.

Não se pode relegar ainda que o homem, como ser simbólico, interpreta e (re)significa constantemente as paisagens com as quais se inter-relaciona, experienciando-as a partir de sentidos que são atribuídos na sua relação de ser-no-mundo tanto aos seus elementos naturais como aos culturais; pois a paisagem "traz a tona a totalidade do ser humano, os seus laços existenciais com a Terra, ou, se se quer, a sua geograficidade original: a Terra como lugar, base e meio da sua realização" (DARDEL, 1952, p.42).

Nas festas, (re)significações momentâneas das paisagens, todavia muitíssimo intensas, podem ser favorecidas pelo estado de "efervescência" e pelas emoções suscitadas, pois "a paisagem se unifica em torno de uma tonalidade afetiva dominante, perfeitamente válida embora refratária à qualquer redução meramente científica" (DARDEL, 1952, p.42).

Talvez não haja mesmo um fenômeno social que nos remeta a uma gama de emoções tão diversas e intensas como a festa, seja pela sua alegria, excitação, admiração, ou mesmo pela aversão, ódio e irritação que despertem. Assim, festa e emoção compõem um binômio indissociável tanto para quem a vivencia como brincante ou assistente, quanto para quem a resgate a fim de investigá-la.

No que se refere à tradição de pesquisa sobre este assunto, não se podem relegar as contribuições de Durkheim (1989) e seu conceito de festa que influenciou (e influencia) toda uma "escola de pensamento": a festa é um estado de "efervescência" e de "excesso" em que o ser humano transporta-se para fora de si mesmo e afasta-se daquilo que lhe preocupa na cotidianidade. Para ele, a efervescência proporciona a aproximação e movimenta as massas, 
enquanto o excesso rompe solenemente "uma proibição". O autor adverte ainda que a vida séria, manifesta no labor cotidiano, é quem traz as condições para o transbordamento da efervescência e dos excessos.

A teoria durkheiminiana encontrou eco em diversos autores, tais como Caillois (s.d.) - que ressalta igualmente a importância deste "momento de efervescência" para a continuidade da rotina e o revigoramento da coletividade pelo retorno ao "caos criador"- e Isambert que, de modo complementar, define a festa como "transgressão ritual" onde há "liberação dos instintos", distinguindo-se dos "ritos cotidianos" pela "amplitude de seus rituais" e da "diversão banal" pela "diversidade da festividade" (1982, p.127). A atitude transgressiva, favorecida pelo estado de efervescência e excessos, foi ainda enfocada por Girard (1990), Bataille (1993) e Duvignaud (1983), o que ratifica a importância do pensamento durkheiminiano e a questão da emoção na festa; sendo esta (a emoção), para Maia (2001), constitutiva de sua espacialidade.

Entretanto, como dissemos logo de início, a festa é um fato social total e não se podem compreender as visões sociais de mundo aí transmitidas apartando-as das diversas instâncias que nela interagem e dos fenômenos sociais que a compõem. Paralelamente, uma paisagem festiva, ainda que passageira, diz muito acerca do lugar, já que esta manifesta a bricolagem de elementos "perenes" (como a natureza e as edificações humanas) e diacrônicos com rituais, linguagens, atores e cenários próprios, entre outros aspectos. Desse modo, como observa Cosgrove, embora o simbolismo da paisagem seja "mais facilmente apreendido nas paisagens mais elaboradas", como a cidade, encontra-se disponível também para interpretação "nas paisagens rurais bem como naquelas aparentemente não-humanizadas" (1989, p. 1125) e, incluiríamos, nas efêmeras paisagens festivas. É nesta perspectiva que, no presente trabalho, recuperamos o ciclo festivo Carnaval-QuaresmaPáscoa na Cidade de Goiás no final do século XIX, entre 1880 e 1899; ou seja, na transição do regime monárquico para o republicano. Neste momento, a Cidade de Goiás assistiu a intensos debates políticos entre republicanos e monarquistas, religiosos e laicos, povo e elite. Procuraremos desvelar como uma "multiplicidade de coisas em movimento", característica do fato social total (MAUSS, 2003), interferiu na dinâmica deste ciclo e como isto se materializava na paisagem, (re)significando os seus elementos. Para tanto, conforme sugere Cosgrove (1989), recorreremos a evidências que nos são dadas em produtos culturais, particularmente em fontes textuais como relatos, notícias, memórias. Acompanhe-nos então nesta visita à Cidade de 
Goiás e às suas festas do carnaval à Páscoa no final do século XIX aceitando o seguinte convite:

\begin{abstract}
Sociedade Carnavalesca Club dos Marmanjos
Participa-se ao respeitável publico d'esta Capital que o Club dos Marmanjos, recentemente organisado, resolveu festejar o primeiro dia de carnaval d'este anno, com um imponente prestito carnavalesco...

Aviza-se aos srs. socios que teem de tomar parte no prestito, que deverão se achar no alto da Santa Barbara as 3 horas da tarde do dia 16 do corrente; outrosim que no sabbado as 8 horas da noite haverá um formidolozo Zé Pereira. (GOYAZ - ORGÃO DEMOCRATA, 12 fev. de 1896, p. 4)
\end{abstract}

\title{
Secos e molhados
}

A apropriação e o povoamento de Goiás oficializado pela coroa portuguesa ocorrem embrionariamente em 1726, quando é criado o Arraial de Sant'Anna, e de jure dez anos mais tarde com a elevação do arraial à categoria de vila por determinação de D. João V. Desde o surgimento de Sant'Anna até 1744, o imenso sertão das minas dos Goyazes respondeu ao poder da temporal da Capitania de São Paulo, enquanto a jurisdição espiritual era dada pelos Bispados do Rio de Janeiro - "cabeceiras do Tocantins, e Cuiabá, às terras de São Pedro do Sul, das alterosas das Minas Gerais ao Guairá" - e do Pará - "bacia tocantina" - (SILVA, 1948, p. 72). Ressalte-se que o primeiro governador da Capitania de Goiás empossou-se junto à Câmara aos 8 de novembro de 1749, oficializando, neste momento, o desmembramento.

Coube a D. Frei Antônio de Guadalupe a criação da freguesia no arraial de Sant'Anna e em outros núcleos de mineração que estavam sob seu báculo. Em 1745, pela bula Condor Lucis Aeternae, do papa Bento XIV, é criada a prelazia de Goiás, com sede em Vila Boa, mas somente o quinto prelado eleito fez sua solene entrada, em 1824, seis anos após ter sido nomeado; pois, dos quatro que o antecederam, dois renunciaram ao cargo e dois morreram a caminho de Goiás. Naquele momento, Goiás já tinha o status de cidade, o qual foi concedido por carta régia de D. João VI, em 1818. No ano de 1826, a Prelazia de Goiás foi elevada à categoria de Bispado pelo papa Leão XII. Porém, o Governo Imperial reconheceu a sua criação apenas no ano seguinte.

Destarte, no final do século XIX, o fato de ter sido arraial de mineração, vila e cidade, além de sede administrativa da capitania, da província e do bispado, ou seja, centro dos poderes temporal e clerical, destacavam- 
se na paisagem urbana da Cidade de Goiás construções como o Palácio do Governo, a casa de câmara e cadeia, as diversas igrejas barrocas, o palácio episcopal e o seminário, com o entourage disposto em casario colonial. Pelas suas ruas estreitas, típicas dos antigos arraiais de mineração, ocorriam os entrudos, Zé pereiras, bandos, desfiles de sociedades carnavalescas, procissões e folias.

Politicamente, o período analisado foi marcado, no ocaso da monarquia, como observa Ferreira, "pela instabilidade governamental, com os presidentes permanecendo muito pouco tempo à frente da administração". Estes, geralmente, após uma rápida passagem por Goiás, eram "substituídos [...] pelos vice- presidentes. E isto se explica: os vice eram sempre tirados dentre os Goianos de valor, enquanto os presidentes eram escolhidos no Rio ou em São Paulo [...] Assim, pouco chegavam até Goiás" (1980, p. 54). As lideranças políticas locais não raro embatiam-se contra o ideário romanizante trazido pelos bispos reformadores, o que desembocava em conflitos entre católicos goianos x católicos romanos sobre as maneiras de se festejar.

Estas elites tinham ainda o controle de jornais que circulavam na cidade, dos quais dispuseram para combater o doutrinário romanizante e ultramontano dos bispos, afrontando o alto clero com a divulgação dos feitos ostensivos dos festeiros (banquetes, cavalhadas, foguetório etc.) e apoiando as irmandades em suas quizilas com a Igreja, conforme a seguinte notícia sobre a festa de Bom Jesus do Passos:

Tendo s. exa. Rvma., não obstante pedidos de pessoas altamente collocadas, segundo nos consta, prohibido a procissão (...) do Sr. Bom Jesus dos Passos, na noite d'amanhã, sob o pretexto de que n'essas procissões, a noite, dão-se factos de desrespeito á moral e á religião; reuniu-se a respectiva irmandade na manhã de domingo, e depois de discutir calorosamente a questão, resolveu officiar a s. exma. Rvma. pedindo a revogação dessa ordem... (GOYAZ, 24 de mar. 1887, p. 3)

No tocante à economia, a Província e, posteriormente, o Estado de Goiás organizava-se, desde a crise da mineração, com base na agropecuária, tornando-se a criação de gado, de acordo com Chaul, "prova inconteste de que a economia goiana se aprumava por meio de uma atividade de maior durabilidade que a exploração do ouro". Chaul observa ainda que, "em 1870, das 105.548 cabeças, 32.949 foram exportadas" (2001, p. 96). Já a agricultura, segundo o autor, durante o Império, permaneceu como atividade secundária, "pois a pecuária trazia maiores divisas em termos de dinheiro líquido" (CHAUL, 2001, p. 103). De outro modo, em termos de produção agrícola, até 
o início do século XX, "a população sertaneja dedicava-se sobretudo à própria subsistência e, de forma secundária, à troca de produtos que excediam às suas necessidades" (BORGES, 2000, p. 94).

Na Cidade de Goiás, no final do Império, além das funções administrativas, havia um modesto setor de transformação de matérias primas (olarias, cortidores e matadouro). Relativamente mais diversificados eram os setores de prestação de serviços e comércio. Para o ano de 1886 Brandão (1978) nos apresenta as seguintes atividades de serviços: advogados (4), médicos (2), engenheiros (3), dentistas (2), bilhar (2), pedreiros (2), barbeiro (1), pintores (3) entre outros. Quanto ao comércio, o mesmo autor enumera na cidade, para aquele mesmo ano, a existência de açougues (3), fogueteiro (1), armazéns (12), tavernas (41), negociantes de fazendas, ferragem e molhados (29) etc.

Cabe ressaltar a existência de uma economia de festa no "sertão goiano", fato bem percebido por Dom Eduardo Duarte e Silva ao comentar sobre o Vigário de Monte Alegre, o qual ele destituiu por considerá-lo de pouca fé, o que descontentou o povo do lugar: "Sem padre, a banda de música, o fogueteiro, o vendeiro, o leiloeiro e o sacristão não ganham dinheiro" (SILVA, 2007, p. 79-85). Na Cidade de Goiás, nota-se que as festas também dinamizavam a economia, pois havia a oportunidade de exibição de si mesmo (tanto homens, mulheres e crianças) como dos cuidados que se tinha com as casas (sujeitas a serem visitadas naquele momento). $\mathrm{O}$ comércio de secos e molhados - compreendendo os secos roupas e acessórios e os molhados, comestíveis e bebidas (CHAVES, 1999) - para as festas ganhava relevância e invadia as ruas, o que é comprovado nos seguintes anúncios:

Para as Festas da Semana Santa

A Casa Bulhões acaba de receber um grande sortimento de rendas pretas de seda, de 8 a 30 centimetros de largura, assim como gregas pretas de seda com vidrilho e galão de seda preta com vidrilho.

Botinas de verniz e de couro clarck, peito inteiriço, proprias para officiaes do exercito e pessoas de gôsto apurado (GOIAZ, 19 de mar. 1896, p. 3 - grifos nossos).

Chegou

Para as Festas de Passos e Semana Santa no Empório da Barateza

Onde chegou um lindo sortimento de fazendas finas modernas para vestidos, objectos de armarinho dentre os quais destaca-se com o BOUQUET L'AMOUR [...], variado sortimento de vinho CERVEJA, cognac das mais acreditadas marcas, tiras bordadas em fina cambraia, rendas de cores, fitas, CHAPEOS pretos á pastora para Sras. meninas, guarda chuva do mais apurado gosto para homens e Sras., colletes, saia 
branca e camizas para Sras.; variado sortimento de louca; interessante sortimento de RELÓGIOS com despertadores; ainda mais...... o ...... PARAIZO das creanças! [...]

Quadros com estampas e molduras douradas para quadros só na casa de MOYZES LOPES ZEDES, onde tem também um TABOLEIRO NA RUA vendendo baratíssimo (GOIAZ, 5 de abr. 1889, p. 4 - grifos nossos)

Para as Festas de Passos,

Superior a merinós pretos, para vestidos de $2 \$$ a $3 \$$ o metro. Completo sortimento de franjas de seda preta e gregas com vidrilho, verdadeira sorpresa em preços.

Luvas de retroz, meia mão.

Pentes para tranças

Fichús pretos bordados... (O PUBLICADOR GOYANO, 27 fev. de 1886, p. 4)

Para as Festas de Passos, Semana Santa e Espírito Santo

A casa de Simão de Souza acaba de receber variado sortimento de roupas finas para homens e rapases e bem assim chapéos modernos para homens, senhoras, rapases e crianças.

Rua Morette Foggia, n 18 Goyaz (GOIAZ, 30 de mar. 1895, p. 3)

Após estas rápidas considerações sobre algumas "coisas em movimento" que se entrelaçavam nas festas da Cidade de Goiás no período analisado, vejamos, mais especificamente, como ocorriam o carnaval e as celebrações religiosas no ciclo que se estendia até a Páscoa.

\section{É carnaval, ninguém leva a mal!}

O clima da Cidade de Goiás corresponde ao grande domínio do tipo tropical semiúmido com duas estações bem definidas: de estiagem e de chuvas. Os meses de Fevereiro, Março e Abril, que comportam o ciclo carnaval-Páscoa, pertencem a esta última. Fevereiro, particularmente, costuma ser acompanhado por chuvas copiosas. Nesta época, a paisagem do cerrado já se encontra tomada pelo verde, contrastando com o tom cinza da intensa nebulosidade na abóbada celeste. "O domínio das águas, inseparável do espaço verde, está ao lado da vida" (DARDEL, 1952, p. 27). O pasto fresco engorda o gado, os últimos frutos dos pequizeiros são coletados e conservados para uso futuro e os produtos plantados no início do período chuvoso já se encontram quase no ponto de colheita. Tudo isto abastecerá com fartura várias festas. 
Em fevereiro, então, as águas de aquário derramam-se sobre Goiás, trazendo fartura, mas também enchentes, preocupação com seu possível excesso sobre as plantações e recolhimento em casa. "A tempestade revela brutalmente a sua vontade de absorver", observa Dardel, que aproveita para definir o domínio das águas como do movimento, mas também da discrição, "de algo reservado e do alívio" (1952, p. 27-8). As poucas evidências que encontramos sobre o carnaval na Cidade de Goiás no período analisado nos mostram essa dualidade. Inspirados em Dardel, dizemos que o carnaval, por vezes, foi para os vilaboenses como uma torrente pondo em movimento a paisagem, noutras, como mero cicio de riachos que passava despercebido. Evidências da aguaceirada nos são fornecidas por notícias e memórias, pois não há registros pluviométricos deste período, tais como:

\section{CHUVAS}

Ha bem annos não temos abundancia de descargas pluviaes, como as que nos amolam desde o principio d'este mez.

O Rio Vermelho tem lambido os muros do predio do Sr. Ignacio de Faria, que nao ha de estar gostando nada de taes familiaridades; a ponte do Carmo tem tido a estiva poucos palmos acima da flor da corrente. O pequeno corrego $M a$ noel Gomez, de ordinario tão limpido e tão cortez cobrio a ponte do theatro durante algumas horas...

O largo do chafariz está um charco... (TRIBUNA LIVRE, 25 de fev. 1883, p. 4).

\section{CHUVAS E ENCHENTES}

Desde o dia 9 até 16 choveu constantemente nesta cidade e nas freguezias visinhas. O rio Vermelho cresceu extraordinariamente e por três vezes saiu do seu leito e escoou-se em bellas catadupas pelas pedreiras da Pinguela grande, o que attrahiu muito povo... (ESTADO DE GOYAZ, 23 de fev. 1895, p. 3).

1888: [dia] $1^{\circ}$ Fevereiro Choveu mto de tarde (MARQUES, 2006, p. 104).

Embora estas evidências relatem chuvas que antecederam ou foram posteriores ao carnaval naqueles anos, nos demonstram a tendência climática de fevereiro. Entretanto, em outras há menção explícita à influência da chuva no desmanche e inclusive na não ocorrência das brincadeiras carnavalescas, cuja paisagem era marcada pela despregadura nas ruas, e não pela confirmação de um axis mundi materializado em certa edificação:

1882: Dia 19 [fevereiro] foi Domingo choveu mto. q.' não [...] haver bando. 1883: Dia 6 [fevereiro] Houve um Banto mto. bonito. ms. desmanchou-se logo pr. causa da Chuva... (MARQUES, 2006, p. 24 e 41) 
No início do nosso trabalho reiteramos o convite da Sociedade Carnavalesca Club dos Marmanjos, no qual se mencionava ainda um formidoloso Zé Pereira. Nas linhas acima notamos referências a bandos. Estes, aliados ao entrudo, eram as manifestações carnavalescas vigentes na Cidade de Goiás no período estudado. Considerando-se ainda as evidências utilizadas, aventamos que o carnaval de rua não era uma festa com infalibilidade ou de grande apelo. Sobre a passagem daquela Sociedade Carnavalesca e do Zé Pereira, por exemplo, após o carnaval noticiou-se:

O carnaval não passou despercebido este anno. Tivemos Zé pereira, não formidoloso, como annunciaram, mas emfim foi Zé pereira e o bando de mascarados - Club dos Marmanjos - agradou geralmente.

Vestidos com luxo e capricho, bem montados, acompanhados por bôa musica. No terceiro dia houve baile em casa do dr. Netto e, segundo informam, foi muito concorrido e bem servido, como costumam ser os bailes do dr. Netto. (GOYAZ ORGAO DEMOCRATA, 22 de fev. 1896, p. 3) .

Já em 1880, o Tribuna Livre publicou duas linhas com a seguinte notícia: "Carnaval - d'esta vez passou inteiramente despercebido entre nós" (14 de fev. de 1880, p. 2). Em 1898, Marques (2006) registrou que, no dia 21 de fevereiro teve Zé Pereira, mas complementa qualificando-o como "muito ruim". Não se pode negligenciar, porém, certa efervescência que o carnaval provocava quando as chuvas não atrapalhavam. No próprio ano de 1882, se no domingo de carnaval não houve bando, conforme se citou anteriormente, na segunda-feira "a tarde hove [sic] um concorrido bando" (MARQUES, 2006, p. 24). Em outros carnavais, a euforia também tomou conta da cidade segundo as palavras de Marques:

1881: Dia 28 [fevereiro] eu e Lili, fomos em caza de Dr. Azeredo; e Silvina veio aqui, e Prescilliana veio brincar entrudo com nós.

1883: Dia 4 [fevereiro] foi Domingo. Pe. Pio esteve aqui. hove bando detarde. denoite Lulú Pitaluga e Te. Cave. veio aqui.

1884: Dia 24 [fevereiro] foi Domingo Antoninha fa. do Sr. Umbellino passou o dia aqui. denoite o entrudo esteve quente pr. toda parte.

Dia 25 Antonio Mel. veio brincar entrudo.

1885: Dia 15 [fevereiro] foi Domingo de Carnaval: hove entrudo mto. forte. detarde D. Brazilina veio aqui.

1886: Dia 7 [março] foi Domingo de entrudo esteve aqui Lidya Fontoura...

Dia 9 Lili fez annos, nessa tarde este mto. quente de entrudo. (MARQUES, 2006, passim)

Não encontramos nenhuma notícia sobre uma "economia de festa carnavalesca" nos jornais consultados, mas a preparação dos bandos, bailes e 
entrudo deveria incentivar o comércio de tecidos, cera, bebidas e comidas, além da contratação de banda de música. A visitação a parentes e amigos nesse período, como aquelas relatadas por Marques (2006), fosse para brincar o entrudo ou não, provavelmente fomentava relações comerciais e trocas (materiais e simbólicas), mesmo que não fossem tão propagandeadas como aquelas relacionadas às celebrações das "festas na Igreja".

\section{Hallelujah Hallelujah Hallelujah}

Não só o carnaval sofria, vez a vez, com intensas precipitações. Há algumas evidências de que estas afetavam também as festas religiosas que ocorriam das Cinzas à Páscoa. Marques (2006), acerca disto, relata-nos a suspensão da procissão de "Sábado de Passos", em 10 de março de 1883, por causa da chuva, a qual só pode sair na terça-feira, dia 13. No ano de 1888 a chuva também, segundo a autora, provocou o adiamento da "procissão das Dores", mesmo assim, quando esta estava ocorrendo, no dia 25 de março, voltou a chover. Já no ano de 1899, comenta Marques, choveu muito no dia 19, mas no fim da tarde houve "procissão dos Passos". Evidência, à maneira de notícia, também nos informa sobre os transtornos que as chuvas provocavam nestas festas:

\footnotetext{
Surpreendida pela chuva, ao sahir da Igreja do Rozario, ao domingo passado, a procissão do Senhor dos Passos foi obrigada a recolher-se logo, tendo percorrido as ruas da Relação, Carmo e Commércio, houve na Igreja da Boa Morte, a noute, sermão pregado pelo Sr. Bispo diocesano (GOYAZ ORGÃO DEMOCRATA, 8 abr. de 1892 , p. 2)
}

Mesmo assim, durante a quaresma, a tendência climática de Goiás é de redução progressiva das chuvas. O cerrado continua verdejante e os agricultores preparam e/ou iniciam a colheita. $\mathrm{O}$ gado gordo, o milho, o arroz e o pequi conservado, entre outros produtos, são fartamente consumidos nas festividades.

Com a redução das chuvas e a proximidade da Páscoa, a paisagem "limpidez de uma afinidade que afeta a carne e o sangue" (DARDEL, 1952, p. 42) - da cidade modificava-se. Floresciam as quaresmeiras e aleluias pinceladas de roxo e amarelo, já o comércio de festa, matizado pelo preto do luto na quaresma, era adornado pela variedade de cores de secos e molhados para a Páscoa, conforme se notou nos anúncios citados anteriormente. Os sons eram dos cânticos e rezas em latim, do repicar dos sinos, da música entoada nas procissões e das águas das últimas chuvas antes da estiagem e do rio Ver- 
melho, nesta época, fazendo jus ao nome. Esta paisagem servia ao período cinzas-Páscoa na Cidade de Goiás, quando se destacavam as seguintes festas:

- a própria celebração das cinzas - iniciava-se o jejum (MARQUES, 2006) e havia atos religiosos nas principais igrejas da cidade, sendo notada a participação do bispo (ESTADO DE GOYAZ, 5 mar. de 1892, p. 2);

- $\quad$ exercícios da quaresma - com celebrações nas igrejas e via sacra (MARQUES, 2006; ESTADO DE GOYAZ, 5 mar. de 1892, p. 2; GOYAZ, 31 mar de 1892, p. 2);

- festa do Senhor Bom Jesus dos Passos (15 dias antes da Aleluia) - organizada pela irmandade do Senhor dos Passos, destacando-se a transladação de imagem, a procissão e a missa, na qual o bispo diocesano costumava realizar o sermão (MARQUES, 2006; ESTADO DE GOYAZ, 24 abr. de 1892, p. 2; TRIBUNA LIVRE, 13 mar. de 1880, p. 3; ESTADO DE GOYAZ, 22 abr. de 1895 , p. 3; O COMMERCIO, 1880, no 27, p. 2).

- festa de Nossa Senhora das Dores (sexta-feira anterior à Paixão) - ocorrência de setenário, culminando com procissão e missa solene (MARQUES, 2006; ESTADO DE GOYAZ, 13 abr. de 1892, p. 2; ESTADO DE GOYAZ, 22 abr. de 1895, p. 3; GAZETA GOYANA, 25 mar. de 1891, p. 3).

- Semana Santa (de domingo de Ramos à Páscoa) - possuía uma ampla agenda de festas, as quais eram acompanhadas pela autoridade diocesana. Entre os principais eventos destacavam-se:

1. Domingo de Ramos - com procissão, missa pontifical, benzedura dos ramos. Aproveitava-se ainda esta ocasião para realizar a prima tonsura nos seminaristas (GOYAZ, 27 mar. de 1896, p. 3, TRIBUNA LIVRE, 27 mar. de 1880, p. 2; ESTADO DE GOYAZ, 8 abr. de 1895, p. 4; ESTADO DE GOYAZ, 7 abr. de 1892, p. 2).

2. Quarta-feira - ofício de trevas (ESTADO DE GOYAZ, 8 abr. de 1895, p. 4,).

3. Quinta-feira - missa, benção dos santos óleos, cerimônia do lava pé e exposição do SS. Sacramento (ESTADO DE GOYAZ, 8 abr. de 1895, p. 4; idem, 7 abr. de 1892, p. 2; idem, 7 abr. de 1892, p. 2).

4. Sexta-feira - missa dos pré-santificados, procissão do Senhor Morto e pregação de sermão (ESTADO DE GOYAZ, 8 abr. de 1895, p. 4; idem, 7 abr. de 1892, p. 2; idem, 7 abr. de 1892, p. 2). 
5. Sábado - bênçãos do fogo novo e do Círio Pascal e missa solene (ESTADO DE GOYAZ, 8 abr. de 1895, p. 4; idem, 7 abr. de 1892, p. 2; idem, 13 abr. de 1892 , p. 2) .

6. Domingo de Páscoa - procissão, missa, benção pontifical e queimação de judas (MARQUES, 2006; ESTADO DE GOYAZ, 8 abr. de 1895 , p. 4).

Além do comércio de festa, o período cinza/Páscoa produzia também trocas simbólicas, pois esta era uma época de piedade e agradecimento ao Senhor, pela sua dor e sofrimento. Isto era demonstrado participando-se das festividades em sua casa (a Igreja), para qual a roça e a cidade afluíam. O recolhimento de esmolas e donativos (em numerário e cera) para a Semana Santa, festa das Dores e dos Passos era condição sine qua non à sua realização e prova daquele agradecimento (ESTADO DE GOYAZ, 22 abr. de 1895, p. 3; ESTADO DE GOYAZ, 13 abr de 1892, p. 2; ESTADO DE GOYAZ, 24 abr. de 1892, p. 2; GAZETA GOYANA, 25 mar. de 1891, p. 3; GOYAZ, 6 abr. de 1895 , p. 4). A solicitação dos donativos era feita pelos próprios bispos em circulares e publicações nos jornais, quando, paralelamente, advertia-se sobre a necessidade de decência nestas festas e ocorrência da maior solenidade possível (SILVA, 1895 e 1899). Entretanto, observava-se a necessidade do culto externo, pois, quem o rejeita "não é cristão" (SILVA, 1899).

\section{Lavando a alma}

A partir das evidências recolhidas, observou-se que as paisagens festivas do ciclo carnaval-Páscoa alteravam-se sensivelmente nos seus tons, sons e movimento, implicando ainda em diferentes formas de participação e interação social dos atores envolvidos. Notou-se que o carnaval, em alguns anos do período considerado, foi inexpressivo, mas, quando ocorria, era relativamente efervescente. Já as festas das cinzas à Páscoa eram indefectíveis e constituíam as suas paisagens festivas ao longo deste ciclo despertando distintas emoções e promovendo interrelações entre a roça e a cidade. Sugerimos que para isto colaboravam os seguintes fatores:

- O período das chuvas - época de trabalho "na roça" (plantio e cuidado com a cultura). Ir para a cidade debaixo de chuva se, por um lado, demonstrava devoção e penitência ao Senhor nas festas da Igreja, tiraria a graça de se brincar entrudo, no qual se 
molhava com limões de cera ou bexigas cheias de água de cheiro aqueles que, por ventura, circulassem pelas ruas da cidade já molhados. Paralelamente, o adiamento por dois ou três dias era possível nas procissões, mas, no carnaval, este era limitado no máximo à terça-feira, pois na quarta-feira já começava o jejum, bastante respeitado naqueles tempos.

- As restritas trocas materiais e simbólicas - no carnaval não se pagavam promessas, tampouco se faziam donativos "ao santo". O comércio de festa carnavalesca era inexpressivo, ou melhor, não nos parecia "romper com o cotidiano" segundo as evidências consideradas. Já as festas das Dores, Passos e Semana Santa eram anunciadas e esperadas como ocasiões especiais de consumo de secos e molhados, de exibição de si mesmo e das casas (dos homens e de Deus). Os comerciantes traziam roupas, acessórios e gêneros alimentícios d'alhures especialmente para estas festas. No momento estudado, as trocas simbólicas entre os homens e o Senhor, mediadas pela Igreja, foram controladas de perto pela autoridade diocesana, que procurou combater os excessos praticados, sem condenar, contudo, o culto externo (diretriz seguida, em geral, pelos bispos reformadores).

- A inexistência de um axis festivus - o carnaval era uma festa caracterizada pela despregadura na rua, estando em toda parte e, por isso mesmo, em lugar algum; diferentemente, por exemplo, do que ocorria nas festas da Igreja, com seu caráter espiralado a partir de um axis mundi: as igrejas. Estas, no período cinzasPáscoa, foram fortemente ressignificadas como a casa de Deus, onde se recebiam bênçãos e sacramentos, pagavam-se promessas, expiavam-se os pecados e glorificava-se a Sua ressurreição.

\section{Referências}

A GRANEL. Goyaz - orgão democrata. Goyaz, 25 jul. 1891, n. ${ }^{\circ}$ 253, p. 3.

BATAILlE, G. Teoria da religião. (Trad. Thadée Klossowski). São Paulo: Ática, 1993. 95 p.

BORGES, B. G. Goiás nos quadros da economia nacional: 1930-1960. Goiânia: Ed. UFG., 2000, $172 \mathrm{p}$.

BRANDÃO, A. J. C. Almanach da Província de Goyaz (para o anno de 1886). Goiânia: Ed. UFG, 1978, $157 \mathrm{p}$. 
CAILLOIS, R. O homem e o sagrado. (Trad. Geminiano C. Franco). Lisboa: Edições 70, S.d., 179 p.

CARNAVAL. Tribuna livre. Goyaz, 14 fev. 1880, no. 7, p. 3.

CASSIRER, E. Antropologia filosófica: ensaio sobre o homem. (Trad. Vicente Felix de Queiroz). 2a ed., São Paulo: Mestre Jou, 1977, 378 p.

CHAUL, N. F. Caminhos de Goiás: da construção da decadência aos limites da modernidade. $2^{\mathrm{a}}$ ed., Goiânia: Ed. UFG., 2001, 253 p.

CHAVES, C. M. das G. Perfeitos Negociantes: mercadores das minas setecentistas. São Paulo: Annablume, 1999, 184 p.

CHEGOU. Goyaz - Orgão Democrata. Goyaz, 5 abr. 1889, n. ${ }^{\circ} 492$ p. 4.

CHUVAS. Tribuna Livre. Goyaz, 25 fev. 1883, nº 265, p. 4.

CHUVAS e Enchentes. Estado de Goyaz. Goyaz, 23 fev. 1895, n 148, p. 3.

COSGROVE, D. Geography is Everywhere: culture and symbolism in Human Geography. In: GREGORY, D., WALFORD, R. (orgs.). Horizons in human geography. London, MacMillan, 1989 , p. $118-35$.

DARDEL, E. L'homme et la terre. Paris : Presses Universitaire de France, 1952, 133 p.

DURKHEIM, É. Formas elementares da vida religiosa. (Trad. Joaquim Pereira Neto). São Paulo: Edições Paulinas, 1989, 536 p.

DUVIGNAUD, J. Festas e civilizações. (Trad. L. F. Raposo Fontenelle). Fortaleza: Universidade Federal do Ceará, 1983, 236 p.

ESTADO DE GOYAZ, Goyaz, sabbado, 5 mar. de 1892, nº 40, p. 2.

. Goyaz, domingo, 24 abr. de 1892, n 47, p. 2.

. Goyaz, quinta-feira, 7 abr. de $1892, \mathrm{n}^{\circ} 45$ p. 2.

. Goyaz, quarta-feira, 13 abr de $1892, n^{\circ} 46$, p. 2-3.

. Goyaz, quarta-feira, 8 abr de 1895 , no 153 , p. 3.

FERREIRA, J. C. Presidentes e governadores de Goiás. Goiânia: Ed.UFG, 1980, 174 p.

FESTIVIDADES Religiosas. O Commercio. Goyaz, anno II, 1880, nº 27, p. 2.

FESTIVIDADES Religiosas. Tribuna Livre. Goyaz, 13 mar. 1880, nº 11, p. 3.

GIRARD, R. A violência e o sagrado. (Trad. Martha Conceição Gambini). $2^{\mathrm{a}}$ ed., São Paulo: Universidade Estadual Paulista, 1990, 410 p.

GOYAZ - Órgão Democrata. Goyaz, quinta-feira, 24 mar. 1887, n. ${ }^{\circ} 79$, p. 3.

. Goyaz, sexta-feira, 8 abr. de $1892, n^{\circ} 340$, p. 2.

. Goyaz, sabbado, 6 abr. de $1895, n^{\circ} 492$, p. 4.

. Goyaz, sabado, 22 fev. de 1896, n. ${ }^{\circ} 524$, p. 3.

. Goyaz, 19 mar. 1896, n. ${ }^{\circ}$ 526, p. 3. 
GOYAZ. Goyaz, segunda-feira, 22 abr. de 1895, $\mathrm{n}^{\circ} 152$.

. Goyaz, sexta-feira, 27 mar. De 1896, nº 179, p. 3.

ISAMBERT, F-A. Le sens du sacré. Paris: Les Éditions de Minuit, 1982, 314 p.

MAIA, C. E. S. O retorno para a festa e a transformação mágica do mundo: nos caminhos da emoção. In: CORREAA, R. L., ROSENDAHL, Z. (orgs). Religião, território e identidade. Rio de Janeiro: Ed. UERJ, 2001, p. 177-199.

MARQUES, A. J.da S. Memorial de lembranças de Anna Joaquina da Silva Marques (Cidade de Goiás 1881-1899). Goiânia: UCG/IPEHBC, 2006.

MAUSS, M. Sociologia e antropologia. (Trad. Paulo Neves). São Paulo: Cosac \& Naify, 2003, 535 p. MORAES, M. A. Sant'Anna. História de uma oligarquia: os Bulhões. Goiânia: Oriente, 1974, 325 p. PARA as Festas de Passos. O publicador Goyano. 27 fev. de 1886, n 53, p. 4

PARA as Festas de Passos, Semana Santa e Espírito Santo. Goyaz. Goyaz, 30 mar. 1895, n. ${ }^{\circ}$ 491, p. 3.

PROCISSÃO de N. S. das Dores. Gazeta Goyana. Goyaz, 25 mar. de 1891, nº 82, p. 3.

SEMANA Santa. Tribuna Livre. Goyaz, 27 mar. de 1880, nº 13 p. 2.

SILVA, (Bispo) E. D. Passagens: autobiografia de Dom Eduardo Silva, bispo de Goyaz. Goiânia: Ed. da UCG, 2007, 273 p.

. Festividades da Semana Santa. In: Estado de Goyaz, 31 mar. de 1895, nº 152, p. 3.

. Pastoral. Sobre o culto interno e externo e regulamento para as festividades e

funcções religiosas. Roma: Scuola Tipográfica Salesiana, 1899, 63 p.

SILVA, (Cônego) J. T. da F. de. Lugares e pessoas: subsídios eclesiásticos para a história de Goiás. São Paulo: Salesianas, 1948, Vol. 1, 467 p.

SOCIEDADE carnavalesca Club dos Marmanjos. Goyaz Orgão Democrata. Goyaz, quarta-feira, 12 fev., $1896, \mathrm{n}^{\circ} 523$, p. 4.

VIA Sacra. Goyaz. Goyaz, 31 mar. 1892, n. ${ }^{\circ} 44$, p. 2.

Carlos Eduardo Silva Maia - Professor Adjunto do Instituto de Estudos Sócio- Ambiental da Universidade Federal de Goiás. 
